Etnográfica

Revista do Centro em Rede de Investigação em

Antropologia

vol. $16(2) \mid 2012$

Vol. $16(2)$

\title{
El policía y el etnógrafo (sospechado): disputa de roles y competencias en un campo en colaboración
}

The policeman and the (suspected) ethnographer: roles and competences in dispute in a co-produced field

\section{Mariana Sirimarco}

\section{(2) OpenEdition}

Journals

Edición electrónica

URL: https://journals.openedition.org/etnografica/1500

DOI: 10.4000/etnografica. 1500

ISSN: 2182-2891

\section{Editor}

Centro em Rede de Investigação em Antropologia

Edición impresa

Fecha de publicación: 1 junio 2012

Paginación: 269-290

ISSN: 0873-6561

\section{Referencia electrónica}

Mariana Sirimarco, «El policía y el etnógrafo (sospechado): disputa de roles y competencias en un campo en colaboración», Etnográfica [En línea], vol. 16 (2) | 2012, Publicado el 26 junio 2012, consultado el 12 febrero 2022. URL: http://journals.openedition.org/etnografica/1500 ; DOI: https:// doi.org/10.4000/etnografica. 1500

\section{(c) (7) (8)}

Etnográfica is licensed under a Creative Commons Attribution-NonCommercial 4.0 International License. 


\section{El policía y el etnógrafo (sospechado): disputa de roles y competencias en un campo en colaboración}

\section{Mariana Sirimarco}

La figura del antropólogo sospechado suele ser, en los inicios del trabajo de campo, una constante. A partir de una experiencia antropológica en el ámbito policial, el objetivo de este trabajo es desarmar esa construcción de recelo, espionaje e intransigencia con que los sujetos enfrentan al etnógrafo y su trabajo, entendiéndola como una instancia a partir de la cual socavar la supuesta autoridad del etnógrafo y negociar los límites de la investigación. Afirmar esto implica sostener que el rol de investigación no resulta una instancia bajo el puro control del antropólogo. Este rol, antes bien, es altamente permeable a las acciones de los sujetos en el campo: desdibujado, disputado y confrontado, el rol del etnógrafo resulta entonces, en virtud de esta pugna de habilidades y competencias, una suerte de empresa en colaboración.

PALABRAS CLAVE: etnógrafo, sospecha, campo en colaboración.

The policeman and the (suspected) ethnographer: roles and competences in dispute in a co-produced field - The figure of the suspicious ethnographer tends to be a constant in early fieldwork. Based on an anthropological experience in police schools, the aim of this article is to dismantle that construction of distrust, espionage and intransigence with which the subjects face both the ethnographer and his study, understanding it as an instance used to undermine his pretended authority and to negotiate the boundaries of the research. To declare this involves sustaining that the role of the research is not under the pure control of the ethnographer. This role, on the contrary, is highly permeable to the actions of the subjects in the field. Blurred, disputed and confronted, the role of the ethnographer thus turns out, by virtue of this conflict of skills and competences, to be a sort of cooperative enterprise.

KEYWORDS: ethnographer, suspicion, field as cooperative enterprise.

SIRIMARCO, Mariana (maikenas@yahoo.com.ar) - CONICET, Facultad de Filosofía y Letras, Universidad de Buenos Aires, Argentina 
EN 1940, EVANS-PRITCHARD ESCRIBÍA, REFLEXIONANDO ACERCA DE SU estudio entre los nuer, que estos son "expertos a la hora de sabotear una investigación", pues frustran constantemente toda clase de esfuerzos para deducir "los hechos más simples y las prácticas más inocentes" y bloquean "las preguntas sobre sus costumbres" con una tenacidad a prueba de etnólogos. Y ejemplificaba esta afirmación con el extracto de un intento de "entrevista":

"Yo: ¿Quién eres tú?

Cuol: Un hombre.

Yo: ¿Cómo te llamas?

Cuol: ¿Quieres saber mi nombre?

Yo: Sí.

Cuol: ¿De verdad quieres saber mi nombre?

Yo: Sí, has venido a visitarme a mi tienda y me gustaría saber quién eres.

Cuol: De acuerdo. Soy Cuol. ¿Cómo te llamas tú?

Yo: Me llamo Pritchard.

Cuol: ¿Cómo se llama tu padre?

Yo: Mi padre se llama también Pritchard.

Cuol: No, eso no puede ser cierto. No puedes llamarte igual que tu padre.

Yo: Así se llama mi linaje. ¿Cómo se llama tu linaje?

Cuol: ¿Quieres saber el nombre de mi linaje?

Yo: Sí.

Cuol: ¿Qué harás, si te lo digo? ¿Te lo llevarás a tu tierra?

Yo: No quiero hacer nada con él. Simplemente quiero conocerlo, puesto que estoy viviendo en tu campamento.

Cuol: Bueno, somos los lou.

Yo: No te he preguntado el nombre de tu tribu. Ya lo sé. Te pregunto el nombre de tu linaje.

Cuol: ¿Por qué quieres saber el nombre de mi linaje?

Yo: No quiero saberlo.

Cuol: Entonces, ¿por qué me lo preguntas? Dame un poco de tabaco" (Evans-Pritchard 1987: 24-25).

Cuol se convierte, en la pluma de Evans-Pritchard, en una suerte de saboteador de información, un hábil representante de una estrategia típicamente nuer - según parece desprenderse de las palabras del etnógrafo. La estrategia de evadir sus preguntas se vuelve incomprensible ante los ojos de éste: el subterfugio, dadas las simples e inocentes cuestiones formuladas, no puede resolverse más que apelando a lo terco y arisco del carácter nuer. Añade el autor:

"Desafío al más paciente de los etnólogos - a que intente avanzar contra esa clase de oposición. Simplemente te vuelves loco. De hecho, después de 
algunas semanas de relacionarse exclusivamente con los nuer, empieza uno a mostrar, si se me permite el retruécano, los síntomas más evidentes de "nuerosis" (Evans-Pritchard 1987: 24-25).

Similar sensación de seguro nos ha invadido, muchas veces, a aquellos que hacemos investigación antropológica. Recuerdo cierta vez en que, haciendo trabajo de campo en una escuela policial, le pregunté al director cuántos alumnos se encontraban realizando determinado curso en ese momento. La respuesta fue menos evasiva que la de Cuol, pero igual de oclusiva: me contestó que no podía darme ese dato, pues se trataba de información sensible que implicaba la seguridad del establecimiento. Según su lógica, conocer la cantidad de estudiantes de ese curso podía llevarme a calcular la cantidad de todos los alumnos de la escuela y ese número podría, a su vez, permitirme calcular datos relativos al personal destinado a vigilar el edificio. Rotundo en su negativa, el director me daba a entender que interesarme por la cantidad de alumnos era curiosear - oblicua pero no tan tangencialmente - en los vericuetos del sistema de seguridad de la escuela.

Mi reacción ante tal respuesta fue el callado asombro. Me apabulló semejante estrategia de negación. Me apabulló, mejor dicho, la ilación argumentativa que la sostenía y que hacía derivar, de una simple pregunta por el alumnado, una potencial intencionalidad de asalto a un establecimiento policial. Me sentí como Evans-Pritchard ante Cuol: fastidiada ante un informante que obstaculizaba - ridículamente - mis serios intentos de investigación. No pude más que leer, en la negativa del director, una clara tendencia a la franca paranoia.

El etnógrafo sospechado es ya un tópico recurrente en la literatura antropológica (Rosaldo 1991; Guber 2001; Herbert 2001; Owens 2003; Wright 2007; Daich y Sirimarco 2009). Se ha dicho que su figura puede convertirse, para aquellos en el campo, en una representación más o menos difusa del poder examinador y el escrutinio, en una suerte de encarnación de la autoridad científica, capaz de recortar al otro como universo de análisis, convertirlo así en objeto y elaborar, sobre ese otro cosificado, un discurso autorizado (Tiscornia 1992). Como parecen sugerir las palabras de Cuol, lo sospechoso de la figura del etnógrafo no pareciera reposar tanto en la posibilidad de construcción de ese discurso científico como en el hecho mismo de la investigación: en la indagación leída como intromisión. O, para volver a la lógica del director de la escuela policial, en el interés en una información que unos y otros codificarán, según sus roles y posicionamientos, como aséptica o como sensible.

Décadas después de la publicación de las evasivas de Cuol, Rosaldo revisaba la experiencia de Evans-Pritchard:

"El trabajador de campo, de un modo muy británico, empieza el diálogo preguntando al nuer su nombre y el de toda su parentela, su linaje. Cuol, 
por toda respuesta, utiliza todo un muestrario de maniobras para resistirse a responder y, a su vez, pregunta: '¿Por qué quiere usted saber el nombre de toda mi familia?'. Y también: ‘¿Qué hará usted con ellos si se lo digo? ¿Se los llevará a su país?'. El narrador, por su parte, interpreta este diálogo en los siguientes términos: 'Hice gala del etnologismo más paciente para contrarrestar esa resistencia. Eso puede volver loco a cualquiera. Y cualquiera, tras varias semanas en el mismo plan, acabaría dando síntomas, más que de neurosis, de 'nuerosis' [...]' Muestra el narrador las resistencias de Cuol, que, desde luego, es todo un cabeza de toro admirable y perverso. Su oposición es muestra del sentido de la libertad y de la independencia común entre los nuer; y se torna perverso en tanto y cuanto esa su resistencia subvierte los 'inocentes' métodos prospectivos de la etnografía. Ello no deja de ser una medida contra la norma de solicitar el nombre que los extranjeros tienen en su primer encuentro. Según el narrador, no obstante, el fallo de ese su primer encuentro radica en el carácter de los nuer, y no en unas circunstancias históricas concretas. Podrá el lector considerar que, dos páginas antes, Evans-Pritchard describía cómo una fuerza armada del gobierno había arrasado un campamento nuer 'dándose al saqueo de las haciendas y buscando mucho más'. Cuol, desde luego, no demostraba hallarse en posesión de un carácter extraño, sino que tenía muy buenas razones para resistirse a cualesquiera interrogatorios que le hiciese cualquier extraño ávido de saber su nombre y el de toda su parentela” (Rosaldo 1991: 142).

La reposición del contexto político - o mejor dicho: el planteo de dicha hipótesis - abre el campo interpretativo. La reticencia de Cuol ya no se asemeja a la obcecación. Su actitud se tiñe, más bien, de sensatez, ante lo que ha dejado de ser una inocente pregunta etnográfica para convertirse en un abierto interrogatorio. La consulta - “¿cuál es el nombre de tu linaje?”rebasa la frontera de la intromisión para volverse franco peligro. Así percibido, cualquier intento de interpelación etnográfica se desliza hacia la indagación policíaca. El intercambio entre Evans-Pritchard y Cuol se transforma entonces en una muestra de esgrima verbal, con ambos luchando palmo a palmo por no perder terreno; el etnógrafo sitiando el discurso del nativo para obtener información, el nativo desviando las preguntas del etnógrafo para no darla.

El presente trabajo pretende detenerse en lo que este episodio entre EvansPritchard y Cuol sólo comienza a sugerir: la clave de lectura que se abre cuando entendemos que todos somos continuamente explicados y posicionados por los otros, continuamente tanteados, contrastados y entendidos (Daich y Sirimarco 2009). Como bien nos demuestra la intervención de Cuol, ni el curso que sigue el análisis es monopolio exclusivo del etnógrafo, ni este rol de investigación 
resulta una instancia sólida e impermeable, bajo el puro control del cientista social. La interacción con el otro implica, necesariamente, que ese rol de investigador en el que uno se acomoda pueda ser desdibujado, disputado, confrontado y hasta utilizado para provecho de esos otros (Sirimarco 2010). ¿Qué sucede, entonces, cuando la resistencia del otro, lejos de ser entendida como capricho, se percibe como un ejercicio de co-construcción del campo? ¿Qué reflexiones se habilitan cuando se asume que también la figura del etnógrafo es una empresa en colaboración? ${ }^{1}$

Las páginas que siguen son un intento por ilustrar esta afirmación, mostrando cómo esta compleja construcción de sospecha, espionaje, recelo e intransigencia con que los sujetos enfrentan al etnógrafo y su trabajo puede muchas veces ser leída como una instancia a partir de la cual socavar la supuesta autoridad del etnógrafo y negociar los límites de la investigación. ${ }^{2}$

Esta aseveración, válida para cualquier etnógrafo en cualquier campo, adquiere sin embargo otra intensidad cuando se trata, como en mi caso, del desarrollo de trabajo de campo en el ámbito policial, es decir, cuando se trata de la interacción con actores sociales habituados a la pesquisa y especializados en la inquisición como herramienta de trabajo. ${ }^{3}$ Cuando se trata, en síntesis, como ya muchos estudiosos han notado, de sumergirse en una investigación tendiente a indagar a los indagadores (Van Maanen 1978; Herbert 2001; Castro y Leirner 2009; Leirner 2009b; Hathazy 2010). ${ }^{4}$ ¿Cómo se conjugan, en estos espacios, la pregunta del antropólogo y la interrogación policial? ¿Cómo se disputan roles, competencias y habilidades cuando el policía y el etnógrafo se interpelan mutuamente?

l Una aclaración necesaria: hablar de la co-construcción del campo implica aludir a que el proceso de investigación, así como el rol del investigador, no son construcciones en cuya manufactura intervenga sola y exclusivamente el cientista social. Sin desconocer la amplia producción académica posmoderna, no es objetivo de este trabajo referir a los aportes hechos, desde este campo, a la cuestión de la polivocalidad de la autoría etnográfica y a la co-construcción del texto etnográfico (Marcus y Fischer 1986; Clifford y Marcus 1986).

2 Esta afirmación resulta especialmente pertinente durante el inicio del trabajo de campo, donde todos los sujetos implicados nos hallamos todavía en una etapa de mutua adaptación y reconocimiento. Los argumentos vertidos en este trabajo deben entenderse, por lo tanto, en el contexto de esos primeros tiempos. Para matizar estas aseveraciones y avanzar en lo que sucede cuando se superan estos recelos y se afianzan las relaciones con los sujetos, ver Daich y Sirimarco (2009).

3 El mismo trabajo de campo viene desarrollándose desde el año 1999 en diferentes escuelas de la Policía Federal Argentina (PFA) y de la Policía de la Provincia de Buenos Aires (PPBA). Para mayores detalles, consultar Sirimarco (2009).

4 La casuística etnográfica en relación a instituciones de estas características - mayormente policiales y militares - es sin dudas más amplia. Las referencias rescatan, de este corpus mayor, sólo algunos trabajos indicativos que desarrollan una puntual reflexión epistemológica y metodológica sobre este aspecto. 


\section{LA ANTROPOLOGÍA COMO LABOR DE INTELIGENCIA}

En el año 2003 inicié mi trabajo de campo en la Escuela Superior de Policía Comisario Mayor Emilio García García de la PPBA, ${ }^{5}$ que era en ese entonces la institución encargada de dictar aquellos cursos de capacitación que debía cumplir el cuadro de oficiales como condición previa y obligatoria para el ascenso a ciertos grados de la jerarquía. Durante mis dos años de trabajo de campo seguí una buena cantidad de los cursos que cumplían los subinspectores - policías de servicio con unos siete años de antigüedad en la institución - para devenir inspectores. ${ }^{6}$ Mi presentación, al inicio de cada uno de ellos, suscitaba, en los alumnos, una y otra vez la misma dinámica: caras de asombro, posturas incómodas, preguntas escépticas.

Yo era, para ellos, una presencia extraña: una mujer joven que deambulaba por la escuela sin portar uniforme, que no era profesora pero entraba a las aulas y se sentaba a un costado con lápiz y papel, que solía interesarse por lo que pasaba y hacer preguntas. A esta seguidilla de rarezas se le sumaba otra: me presentaba como una antropóloga haciendo trabajo de campo para su tesis de doctorado. Esto, que para mí era una explicación, era, para ellos, otro motivo de sospecha. En un ámbito poco acostumbrado a tener "extraños” en su interior - mucho menos académicos -, la pregunta implícita resonaba en cada silencio receloso: ¿qué era, en primer término, la antropología? ¿Y qué hacía, finalmente, una antropóloga, en medio de las aulas de la policía? (Sirimarco 2009; Daich y Sirimarco 2009).

La duda que suscitaba la posible combinación entre la antropología y el estudio de la policía se resolvía de maneras variadas. Todas implicaban, sin embargo, constantes indagaciones acerca de mi trabajo, de mi filiación laboral y, sobre todo, de la instancia que legitimaba mi presencia en la escuela: ¿qué era lo que intentaba analizar observándolos?, ¿la investigación era a título personal o estaba encargada por alguna institución?, ¿estaba autorizada por el Director o más bien por el Ministerio de Seguridad? Las más de las veces, las preguntas nacían del interés. Otras pocas, del temor. En esos casos, el tono de voz alcanzaba la seriedad, el trato viraba al "usted" y el alumno-policía me

5 La Escuela Superior de Policía Comisario Mayor Emilio García García era un Instituto de Enseñanza Superior, dependiente de la Dirección General de Institutos Policiales de la Subsecretaría de Formación y Capacitación del Ministerio de Seguridad, a través de la Dirección de Formación Básica y Superior. En el año 2005, la Escuela Superior fue subsumida en sus funciones por el Centro de Altos Estudios en Especialidades Policiales.

6 Se dictaban tres cursos (convocatorias) por año, con unos nueve grupos en cada uno (a razón de un grupo por aula), lo que significa que durante mis dos años de trabajo de campo seguí distintas asignaturas en más de veinte aulas. Como se puede apreciar, mi trabajo de campo tuvo, por lo tanto, aula a aula y convocatoria a convocatoria, varios "momentos iniciales". La etapa del recelo fue, por todo lo dicho, de amplia recurrencia en el tiempo y, por ello mismo, de fuerte incidencia en el curso de mi investigación. 
preguntaba, lápiz en mano y en disposición de tomar nota: “¿cuál es su apellido, señorita?"

Una mañana uno de los alumnos pareció despejar la incógnita que anudaba la antropología al estudio de la agencia policial. Charlaba con un par de ellos luego de terminada una clase. Uno no terminaba de entender la vinculación entre la disciplina y mi trabajo de campo en la Escuela Superior. No terminaba de entender, concretamente, a qué me dedicaba y qué quería ver ahí, en las aulas. Mis muchas - y se conoce que no muy buenas - explicaciones no contribuían demasiado a su comprensión. Entonces el otro policía, que hasta ese momento había estado escuchando en silencio a su lado, lo ayudó a entender con una analogía: "como si fuera Inteligencia nuestra" (Sirimarco 2009; Daich y Sirimarco 2009).

Recordé entonces una entrevista que le había hecho, años atrás, a un agente de la PFA. Hablando sobre la presencia adusta y la actitud vigilante que se supone que debe cumplir el policía que está en la calle de "parada", ${ }^{7}$ yo le preguntaba cómo explicaba que estuvieran, en cambio,

"Mariana: [...] todos paraditos, charlando con el quiosquero, haciendo relaciones públicas con las vecinas del barrio...

Agente: Sí, bueno, pero es un procedimiento de inteligencia, porque el policía que está conversando está recaudando información de todo el vecindario. Y tomando confianza con la persona. Vos vas a hablar, por ejemplo, de Boca-River, y la persona va a empezar a agarrar confianza en los policías, y le va a contar. Si vos sabés que aquel se droga, si él roba...

Mariana: ¿Eso no es chusmerío barato?

A: No. Eso es inteligencia".

Ambas situaciones me ayudaron a comprender mi rol en el campo. O mejor dicho, el entendimiento que los otros hacían de mi presencia en la escuela. El policía que había urdido la analogía sin dudas no estaba explicándole al otro el cariz temático de mi trabajo académico, sino pasándole en claro los alcances y especificidades de (su comprensión de) la labor antropológica en tanto metodología de investigación. A la pregunta implícita del primer policía - ¿qué hacés acá, dentro de las aulas, cargando lápiz y papel? - el segundo contesta de manera contundente: hace investigación. Es decir: hace inteligencia: observa, merodea, conversa, genera confianza, hace hablar al otro. En una palabra: se mezcla y recauda información.

La labor de inteligencia ha sido definida como "la actividad consistente en la obtención, reunión, sistematización y análisis de la información específica

7 Así se denomina al puesto en la intersección de dos calles, con la finalidad de brindar funciones de seguridad. 
referida a los hechos, amenazas, riesgos y conflictos que afecten la seguridad exterior e interior de la Nación o Estado". ${ }^{8}$ Como bien sostiene una reconocida figura de la teorización policial, la obtención de datos e indicios es vital para el desarrollo de la labor policial en lo que ésta tiene de prevención del delito y consecución de la seguridad: la inteligencia es una metodología de investigación orientada a la recolección de información, de modo tal que, a su vez, el producto final de la información es la inteligencia (Escobar 1979, 1987).

No otra cosa parece explicarme el agente mencionado anteriormente. No importa aquí si la categorización de "inteligencia" resulta adecuada o no a las labores que enumera: si tal denominación implica una exageración de su quehacer cotidiano en la calle o una mera justificación para la conversación o el curioseo. Lo interesante es, justamente, que el charlar con las vecinas o con el quiosquero pueda ser decodificado en dichos términos. Es decir, que la charla cotidiana, la pregunta intrascendente, la observación o el interés por el otro puedan ser intelectualizados como una metodología de investigación y de extracción de información útil. En síntesis, que puedan ser reflexionados como una forma sutil e imperceptible de la indagación policial.

Hablar de lo sutil e imperceptible es remitir, sin dudas, a un componente fundamental de la labor de inteligencia: el secreto. La inteligencia policial se monta sobre ello: para devenir exitosa requiere no ser evidente. Necesita que la persona, según las palabras del agente, cuente sin saber que lo está haciendo (o que lo haga sin saber ante quién). ${ }^{9}$ La función de la labor de inteligencia se finca en el poder saber sin tener que preguntar:

"Llevaba algunos días haciendo trabajo de campo en la escuela, en el Aula 4. Una mañana, varios días después, me presento en el Aula 2. Repito mi explicación de quién soy y qué estoy haciendo ahí. Uno de los policías, sonriendo, dice: 'ya sabíamos: hacemos inteligencia'. E inmediatamente explica, ante la cara de asombro de la profesora: 'porque si nosotros preguntamos corremos el riesgo de que nos mientan'”.

8 Ley 25.520 de Inteligencia Nacional de la República de Argentina.

9 El aire de secreto que rodea a esta metodología indagatoria es tanto que me fue imposible dar con escritos policiales que me aclararan sus particularidades. Revisando manuales y libros específicos, sólo encontraba titulares y generalidades vacías. Di en un portal de ventas con un texto que, a juzgar por su título y su índice, prometía mucho: "Manual de Inteligencia". Al efectivizar la compra, vi que el tomo I, el que tenía en mano, sólo abarcaba los primeros VII capítulos del índice, todos intrascendentes. Lo interesante parecía contenerse en los capítulos siguientes, pero, tal como rezaba una advertencia en la primera página, "la segunda parte del 'Manual de Inteligencia' (Capítulos VIII al XI) está reservada a los alumnos de las distintas Escuelas y Curos de las FF. AA., de Seguridad, Policiales (nacionales y provinciales), sus integrantes y organismos, entidades o funcionarios afines con la temática desarrollada en su contenido" (Escobar 1979: 3). No pude dar con ese segundo tomo. 
El recurso a la inteligencia como metodología parece sostenerse en un campo donde la pregunta directa resulta imposible o, extrapolando la situación a ámbitos más pedestres, donde se parte de la presunción de la mentira. La inteligencia se vuelve sinónimo necesario del espionaje en tanto necesita, por definición tautológica, sortear un engaño. En este campo de entendimiento, es claro que la inteligencia no sólo apunta a la obtención de información, sino a la obtención de información verdadera: el hallazgo de la verdad es tal vez el producto último de esta modalidad indagatoria. La inteligencia le brinda, al policía, la posibilidad de meterse de lleno en el caudal informativo y de extraer de él el dato verdadero, eludiendo, en base a técnicas agudas pero solapadas de indagación, el probable intento de simulación de los otros.

Así entendida, la labor de inteligencia se convierte en el desarrollo de una contienda: en una lucha por encontrar la verdad en un escenario plagado de disimulos y falsedades. Porque el otro miente, la verdad tiene que ser extraída. El policía abocado a estas funciones se vuelve, entonces, un "delicado técnico, [un] avezado profesional, [un] vocacional artesano [...] cimiento del verdadero duelo, de la real compulsa de voluntades, de la depurada esgrima de ingenios y ardides" en que se transforma ese complejo mecanismo de la indagación policial (Escobar 1987: 282).

Ese mecanismo pareciera asemejarse bastante, a los ojos de estos policías, a la investigación antropológica. O mejor dicho: a lo que el antropólogo hace cuando hace trabajo de campo. Yo era, para ellos, alguien cuyo métier era difícil de asimilar. Y no sólo a raíz de mi presentación - ¿cuántas veces se ha visto un etnógrafo en medio de una escuela policial? -, sino tal vez aun más por las tareas concretas de mi investigación. Yo entraba a las aulas, deambulaba por los pasillos, tomaba café en la sala de profesores, anotaba lo que hacían y decían, observaba lo que pasaba. Esto es: permanecía. Era una presencia constante, que estaba allí, compartiendo con ellos tiempos y espacios y estableciendo con ellos lazos de sociabilidad. Lo que hacía parecía no tener una duración estipulada ni un objetivo concreto fácilmente identificable. Mis charlas con ellos eran cotidianas, mis puntos de interés pecaban - a sus ojos - de baladíes. Mi presencia era tan fuertemente visible como silenciosa parecía ser mi investigación.

En ese clima de sigilos y sospechas con que parecía teñirse mi trabajo, la figura del etnógrafo adquiría tintes brumosos y se acercaba a la del policía en labor de inteligencia. Ese transcurrir con el fluir de los otros, ese "estar ahí" para escuchar y observar y tomar nota, sin necesariamente preguntar a boca de jarro, no hacía más que actualizar, ante la mirada policial, un ejercicio de indagación por ellos bien conocido: el de la infiltración y la generación de confianza como método de obtención de información. ${ }^{10}$ 
Podría argumentarse que este anudar la etnografía y la inteligencia no es más que un simple acto reflejo policial de resolver una incógnita a través de la apelación al propio ámbito. Que el policía, acostumbrado a comerciar con la mentira, el engaño y la sospecha, extrapola estas coordenadas de entendimiento a toda indagación. Tal afirmación, aunque seguramente factible, resultaría sin embargo incompleta. Al cargar las tintas en las particularidades de los otros - en este caso, policías -, deja fuera de la vista los vericuetos de la propia disciplina: tilda de paranoia lo que puede ser prudencia (recordemos una vez más a Cuol y a Evans-Pritchard) y esteriliza la complejidad de interesarse activamente por la vida de los otros. En una palabra, empaña la reflexión acerca de las particularidades y consecuencias con que se desarrolla la investigación etnográfica.

Conviene hacer una salvedad. Acercarse a la vecindad del métier de policías y cientistas sociales en tanto "indagadores" no implica desconocer la divergencia entre los modos con que unos y otros se relacionan con la búsqueda y el sentido último de la información. Mucho se ha tematizado acerca de las contigüidades existentes entre distintas clases de indagadores profesionales: detectives, analistas, jueces, abogados, antropólogos, inquisidores (Žižek 2000; Ginzburg 2006; Mendes de Miranda 2001, 2005; Kandel 1992). Con el objetivo de no caer en repeticiones, conviene sólo recordar, grosera y sucintamente, que policías y etnógrafos solemos direccionar de manera diferencial nuestras pesquisas. Si los primeros buscan una verdad única y hallable, los segundos persiguen discursos múltiples y constituidos. La labor de inteligencia presupone un dato externo y extraíble; la labor etnográfica, una información construida. En este contrapunto, las finalidades de la investigación marcan asimismo una divisoria de aguas: el policía está inmerso en un sistema burocrático-penal que tiene como función el descubrimiento de hechos y la asignación de responsabilidad social. El etnógrafo, por el contrario, bucea en áreas donde dominan la explicación y el significado de las prácticas sociales. Podría decirse que la diferencia entre unos y otros es la que lleva de la información recaudada al conocimiento producido.

Mencionaba anteriormente que resulta incompleto entender la postura policial que anuda etnografía e inteligencia como una mera remisión a lo propio. Tal vez podría pensarse que son justamente estos intereses diferentes acerca del para qué de la indagación los que refuerzan las semejanzas respecto de ciertas aristas del cómo. Quiero decir: cuando, ante sus ojos, el producto final de una investigación social se dilata y se vuelve casi intangible por lo demorado (las tesis llevan tiempo, las ponencias circulan en otros ámbitos), ${ }^{11}$

11 No quiero dar a entender, con esta afirmación, que la investigación antropológica no produzca conocimiento más que en sus postrimerías, ni que éste circule ajeno a los sujetos en el campo. Tal afirmación sólo alude a ese momento de trabajo de campo temprano en que este artículo se enmarca y donde es entendible que los productos de una investigación sean menos frecuentes. 
el mero transcurrir del proceso de investigación se intensifica, ocupando un presente permanente.

Cuando no hay nota periodística, ni informe burocrático, ni grilla de preguntas que funcione legitimando esa pretendida investigación social, ese mero acontecer se vuelve entonces lo único visible: lo único que se recorta como instancia fácilmente accesible de la investigación. El trabajo de campo que la guía se vuelve casi su producto: lo único que parece hacer el antropólogo (lo único tangible para ellos) es "estar ahí" escuchando y observando lo que pasa. Lo que la mirada policial devuelve es la imagen de un investigador social que sólo parece estar allí para recabar información (sin que termine de saberse qué hace concretamente con ella). En ese contexto donde el trabajo de campo basado en la observación participante se magnifica, no puede realmente sorprendernos que el método etnográfico se solape con la labor de inteligencia. Lo que se afirma, al sostener esta suerte de equivalencia entre antropología e inteligencia, no es otra cosa, finalmente, que el sustrato común de policía y etnógrafo en tanto indagadores.

\section{EL ANTROPÓLOGO COMO ESPÍA}

Mencionaba anteriormente que en el ámbito policial, tal vez a causa de esa separación tajante que la fuerza policial despliega entre ella y la sociedad civil, la circulación de éstos últimos al interior de la fuerza - de aquellos que no guardan con ella ninguna relación de dependencia laboral o de parentesco - se ha consolidado como un hábito desacostumbrado (Sirimarco 2009; Daich y Sirimarco 2009). En este contexto, y en razón de los argumentos esgrimidos precedentemente, si se declara no ser policía y se viste de "civil", ${ }^{12}$ lo más probable es que no se lo sea, sino que se lo aparente:

"Entonces cuando a vos te presentan, o te ponen gente, como en este caso vos, en un aula, vos decís: '¿qué función cumple, cuál es?' A lo que voy es que, de golpe y porrazo, te ponen un civil, entre comillas, que no es instructor, que no es alguien que te va a dar cátedra. ¿Y qué, nos están estudiando? ¿Qué es lo que quieren averiguar? Porque no preguntan, directamente. ¿Qué es lo que están utilizando? Una inteligencia para saber... Esa es la imagen que a uno le da".

Como bien lo demuestra esta opinión de uno de los alumnos de la escuela, entender mi trabajo de campo en tanto "inteligencia" implicaba dos movimientos principales y concatenados. El primero: que mi objetivo era la búsqueda de

12 Retomo la categoría tal como ellos la utilizan: para aludir a todo aquel que no pertenece a una fuerza de seguridad. 
información. El segundo: que la buscaba para elevarla a una instancia superior. El planteo de mi investigación en estos términos sentaba la base para que la figura siempre sospechada del antropólogo se ratificara certeramente como espionaje, pues, como bien señala Szasz, "el lenguaje con el que se formula un problema social o personal, proporciona velada pero inexorablemente su solución" (1977: 313). Así, en esta contigüidad entre etnografía e inteligencia, la certidumbre de la espía venía dada de antemano. ${ }^{13}$

Una vez confirmado este movimiento, el siguiente era predecible: si la Inteligencia es una labor de indagación realizada, al menos por definición, por órganos estatales ${ }^{14}$ ¿quién más que el poder de gobierno provincial o la misma policía intentaría un ejercicio de inteligencia con ellos?

"Aula 7, en la hora de Psicología. De repente, mediada la clase, G. se vuelve hacia la profesora y le pregunta qué era realmente lo que yo hacía, si yo hacía realmente lo que había dicho que hacía. Lo miro directamente:

M: ¿Cuál es concretamente la pregunta?

G.: ¿Cuál es su función, señorita? - me dice, en abierto tono intimidatorio.

Le contesto lo que ya les había dicho, que estaba haciendo trabajo de campo para mi tesis de doctorado en Antropología. Vuelve con la pregunta de si los estaba investigando a ellos. Al rato me dice que había venido alguien haciendo comentarios sobre mí, diciendo que yo hacía una investigación, pero para el Ministerio. Los demás apoyaron lo que decía, adhiriendo a la existencia del rumor. Les aclaro nuevamente que eso no era cierto, que yo ya les había dicho lo que hacía y que no trabajaba para ningún Ministerio.

El clima se pone tenso. Muchos empiezan a decirme que no le hiciera caso a G., otros le sugieren que deje la botella. Otro luego me explica que G. se sentía perseguido porque era jefe de destacamento y le tenía miedo al Ministerio. Me confirma también que fue un rumor de pasillo, surgido tal vez de ellos mismos, de charlar y comentarse 'mirá si va a ser cierto que está viniendo acá para hacer un trabajo, debe ser del Ministerio'”.

13 Desde aquella famosa denuncia de Franz Boas respecto del rol de espías de algunos antropólogos norteamericanos, la reflexión acerca de las posibles ligazones entre etnografía y espionaje tiene larga data. Si bien el eje de este trabajo discurre por otros carriles, es interesante la vertiente de análisis que se abre cuando esta "sospecha" por la labor de indagación del cientista social queda confirmada en tanto labor de real espionaje. Para profundizar en torno a la interacción entre la disciplina antropológica y las agencias de inteligencia durante contextos de guerra y el uso del conocimiento antropológico en ellos, ver Price (2002a, 2002b, 2002c) y Leirner (2009b). Para un interesante análisis sobre la intención del ejército de cooptar al antropólogo como (un supuesto doble) espía, ver Leirner (2009a).

14 Ver Ley 25.520 de Inteligencia Nacional de la República de Argentina. 
El Ministerio de Seguridad de la Provincia de Buenos Aires funciona, en el discurso de los alumnos de la escuela, como una instancia panóptica de control: omnipresente, siempre al acecho y siempre vigilante de sus palabras y de sus actos. Vale aclarar que el Ministerio no es otra cosa que el remozamiento político de lo que fuera tradicionalmente la Jefatura de Policía. ${ }^{15}$ En el imponente edificio sobreviven las marcas de ese pasado institucional: la enorme escultura de un gallo en la recepción, una placa conmemorando a los que dieron la vida por la patria, una sala dedicada a los caídos en cumplimiento del deber, vidrios esmerilados con el escudo de la PPBA, una capilla en el segundo patio. Tal vez sea un error señalar que esas marcas sobreviven: más bien son prueba de lo que para el personal policial es una continuidad indiscutible. ${ }^{16}$ Como ellos mismos lo resumen: "el Ministerio sigue siendo la Jefatura, por más que metan civiles ahí adentro". Es claro que, a la luz de este razonamiento, mi calidad de "civil" no hacía más que ahondar mi percepción de espía del Ministerio. De espía no sólo del poder político sino, siguiendo esta argumentación, de lo que dicha dependencia tiene aun de Jefatura, esto es, por lo que todavía hay en él de policial (Sirimarco 2009).

Afirmar esto implica entender que la actitud con que los otros reaccionan a nuestras preguntas y observaciones no obedece únicamente a una reserva individual que lleva a decodificar al etnógrafo como un intruso profesional avanzando sobre ámbitos privados. Sobre esta posibilidad se monta otra, si se quiere más acuciante: la sensibilidad que resulta del contexto institucional y político del que ese otro es parte. Durante mi trabajo de campo, los alumnos no hacían sino mostrarse extremadamente cautos frente a diversos vaivenes políticos ${ }^{17}$ que - sentían - los dejaban vulnerables.

Más allá de que la sensación de desprotección frente al poder político resulta un tópico recurrente en el discurso policial (tópico que no debe llamar a engaño respecto de la compleja trama de vinculaciones y dependencias que vincula a la organización policial con estructuras de gobierno), no es menos cierto que el personal subalterno - tanto más cuando es alumno - tiene motivos fundados para la prudencia y el temor. En una institución fuertemente jerarquizada, los controles son estrictos y no siempre se encuentran reglamentados.

15 "El Señor Ministro Secretario de Justicia y Seguridad ejercerá la conducción orgánica de las Policías de la Provincia de Buenos Aires y las representará oficialmente" (Ley 12.155 de Organización de las Policías de la Provincia de Buenos Aires, art. 4).

16 La continuidad se expresa también en la arquitectura. En el frente del edificio, un cartel colocado en un costado reza que se trata de la Jefatura de Policía, "siempre al servicio de la comunidad". Una placa en el piso dice, en cambio, que se trata del Ministerio de Justicia y Seguridad. En letras de molde, en la fachada, se aclara a su vez que tal inmueble corresponde al Ministerio de Seguridad. La superposición - la sucesión de cambios - se anuda en una confusa cartografía.

17 Me refiero a los procesos de reforma de la seguridad pública que con pausas, avances y retrocesos, venían teniendo lugar desde el año 1998. 
La probabilidad de que alguien sea acusado y punido por algún hecho o falta no codificada alcanza niveles elevados. En ese marco de situación, cualquier información "indebida" puede desembocar en la posibilidad de una sanción.

La presencia de un extraño - léase de un civil - puede claramente reforzar este contexto de precaución generalizada (se recordará que los alumnos eran policías en función, con jefes, responsabilidades y obligaciones que excedían las del ámbito escolar). Recuerdo una tarde del año 2004 en que un partido de fútbol de Argentina se superponía con una conferencia a la que los alumnos debían asistir. Cinco de ellos, según relataron después, se quedaron viendo el partido y tomando unas cervezas. Al otro día, para justificar la falta, presentaron, los cinco, las debidas constancias escritas de su puño y letra en las papeletas oficiales correspondientes. En una de ellas el causante manifestaba una

"indigestión estomacal, debido a que la comida del mediodía me produjo cólico intestinal y vómitos. Habiendo permanecido en el horario de la conferencia en reposo (Hotel Círculo Oficiales) hasta el día de la fecha y siguiendo poseyendo los mismos síntomas. De ser necesario ante Ud. presentaré certificado médico. Que es el motivo por el cual no me presenté en la tarde y la primera falta que tengo desde que comencé el curso".

Estaba en el aula con ellos cuando los alumnos me mostraron estas constancias que iban a presentar ante la dirección de la escuela. Pensando en cómo éstas podrían ilustrar perfectamente la construcción de lo corporal como ámbito a partir del cual actuar la resistencia a la disciplina escolar (uno de los capítulos de mi tesis), les pedí permiso para fotocopiar una de ellas y salí rumbo al quiosco. Cuando volví al aula, la profesora, que había participado de toda la charla previa, me cuenta que a mi salida "había estallado la paranoia y se habían quedado perseguidos" por toda la situación. No pude más que asombrarme de todo esto, preguntándome (y preguntándoles) cuál era el temor de que fotocopiara un papel que ellos mismos iban a presentar ante las autoridades de la escuela. ${ }^{18}$

Mientras yo veía en esas constancias un mero soporte a partir del cual desarrollar ciertas conceptualizaciones generales, ellos veían información que podría colarse, a través de complejos vericuetos institucionales, y devenir prueba de alguna clase de culpabilidad. Lo que para mí no era más que un ejemplo sugerente de ejercicio de la resistencia, era para ellos la potencial materialización de una falta. El acto de fotocopiar la constancia activó el proceso de sospecha: de simple excusa de circulación interna viró hacia información eventualmente comprometedora. 
Los ejemplos hasta aquí mencionados bastan para sugerir por qué mi figura resultaba, si no abiertamente intimidante, al menos esquiva en su comprensión. ${ }^{19} \mathrm{Mi}$ llegada a las aulas era recibida, entre risas, con una frase de rigor y cierto tono conspiratorio: "mirá, ya vienen a observarnos". Las alusiones no siempre quedaban en el plano del comentario descriptivo. Una vez, durante una clase, uno de los alumnos fue llamado por un trámite, volviendo a los pocos minutos. Ni bien regresó al aula, otro de sus compañeros me miró y dijo, sonriendo con picardía: "fue a cambiar la cinta". La insinuación era obvia: existía un aparato de grabación escondido (y manipulable, por ellos, desde el exterior) que estaba registrando también lo que yo decía.

Vale establecer una pausa para aclarar que la lectura de tales situaciones no debe dar la equivocada idea de un ambiente tenso y agresivo, surcado por comentarios amenazantes y miradas recelosas. Salvo contadas excepciones, se trataba, por el contrario, de un clima agradable, donde la referencia al espionaje se resolvía mediante la broma. La jocosidad no invalidaba, de todos modos, la seriedad de la sospecha, y chistes, chicanas e ironías estaban a la orden del día para recordarme, finalmente, lo actual que seguía siendo ese recelo.

Recelosos pero - tal vez a raíz de ello - también ellos manipuladores de la amenaza, de lo que se trataba era, en última instancia, de devolverme la sensación de intimidación que mi presencia les generaba. De hacerme sentir controlada y de ratificar, sobre todo, un movimiento que devolvía la paridad a la relación entre policías y etnógrafo. Un movimiento que los regresaba a ellos a ese locus de indagador conminatorio con que el funcionario policial hábilmente comercia. De lo que se trataba, en síntesis, era de disputar el monopolio de ciertas competencias:

"Recreo. Vuelvo al aula 2, a pedir voluntarios para una charla. Luego de un silencio tan largo como incómodo, B. se ofrece. No faltan las risas y los chistes, al mejor estilo de colegio secundario. Llueven las recomendaciones para el candidateado: al menos, que yo le pague el almuerzo. En medio de las bromas, le pregunto si no tiene problemas en que la charla sea con grabador.

19 Si bien este artículo hace foco en la percepción y reacción de los alumnos, debo aclarar que no me refiero sólo a ellos. Compartiendo aulas, tomando café con los profesores, charlando en el despacho del director, finalmente resultaba sospechada por casi todos. Los alumnos maliciaban que fuera una espía encubierta del Ministerio. Los docentes (sobre todo los que eran a su vez policías), que fuera una soplona del director. Mi presencia representaba la posibilidad de acceso a los espacios y el temor de posesión de información vivenciada como comprometida. En tanto nadie estaba seguro de cuál era el tenor de los datos que supuestamente me interesaban - esto es: en tanto nadie parecía confiar completamente en mi rol de antropóloga en trabajo de campo para su tesis - la situación resultaba bastante confusa, con alumnos-policías temiendo por las consecuencias de sus opiniones, con docentes recelando por los corolarios de las suyas y, debo decirlo, con un director que parecía saber sacar provecho de este estado de sospecha generalizada. 
Me contesta algo que suscita la carcajada general: ‘¿y yo puedo ir con una pistola con silenciador?'”.

Esta respuesta, que se queda a medio camino de ser una broma y se vuelve muy fácilmente "apriete", es justamente por esto interesante. Lo es por las percepciones que deja entrever, donde la tenencia de un grabador que pudiese comprometer al policía se contrarresta con "la pistola con silenciador" que pudiera protegerlo. Si el uno es, ante sus ojos, riesgoso, la otra es, en sus manos, defensiva. Ambos objetos portan identidades, condensando sentidos de pertenencia profesional. Ante un grabador percibido como amenazante - lo es por sugerir que todo lo que diga será grabado -, el arma se transforma en un recurso que encarna el paradigma de la fuerza y la violencia y que inviste al policía como sujeto activo del control de los otros.

Como este ejemplo sugiere, el arma no necesita desenvainarse para ser usada: su uso puede ser muchas veces discursivo. En un escenario reglamentario que indica que cualquier sitio de guardado ajeno a la cartuchera es ostentación y merece ser penalizado (el arma sólo puede ser sacada de ella para disparar), aun su exhibición narrativa adquiere una significación particular como elemento disuasorio y coactivo. Es en este plano - no por simbólico menos real - que el arma se convierte en una manifestación del poder policial: no tanto, en este caso, por lo que su uso efectivo conlleva, sino por lo que la amenaza de su uso sugiere (Sirimarco 2006).

En esta tónica - y como demostración de que las puniciones efectivamente tienen lugar -, baste mencionar que, durante mi trabajo de campo, dos policías fueron sancionados por uso indebido del arma. El relato de lo sucedido me fue hecho por el director del establecimiento. Los alumnos de un curso extracurricular que se estaba dictando en esos días estaban mirando una película, solos en el aula. El film mostró, en un momento, una escena de un policía obligado a consumir droga, pistola en la cabeza mediante. Parece ser que uno de los alumnos, a modo de chanza, repitió la escena en la cabeza de otro compañero, que le festejó la broma. Alguien los vio y elevó la denuncia. Hasta lo que pude saber del caso, los dos policías habían sido sancionados: uno por uso indebido del arma y otro por encubrimiento (al parecer había intentado defender a su compañero diciendo que la broma había sido hecha con la mano y no con la pistola). Se había pedido, además, un psicotécnico para ver si estaban en condiciones de portar armas y se estaba evaluando, si mal no recuerdo, su expulsión de la escuela.

Como se ve, los usos reales y discursivos del arma no eran ajenos a otros contextos y a otras interacciones. Quiero decir: no eran material exclusivamente urdido ante la figura del etnógrafo. Comentarios de igual tono al hecho ante mí eran recurrentes, por ejemplo, en instancias de parciales. Recuerdo que una mañana, ante una evaluación escrita en la asignatura "Psicología", uno de 
los policías deslizó, mientras preparaba la hoja para el examen, una suerte de chanza velada de amenaza: "es la primera vez que pongo balas en la recámara". Otra mañana, ante la entrega de exámenes en esa misma materia ${ }^{20}$ un policía que entró tarde a clase se detuvo ante la profesora, con la mano encima del arma, y comentó: "estamos todos aprobados, ¿no?"

Ningún policía verá, en estas situaciones, más que chistes. ${ }^{21}$ Conviene recordar, sin embargo, la estrecha ligazón que une al humor con el cuestionamiento y hasta el desafío de la autoridad de los otros (Fonseca 2000), donde el chiste es el instrumento que permite decir, veladamente, aquello que no puede o no quiere decirse de frente. El "chiste" del arma opera entonces detectando un escenario intimidatorio y reaccionando en consecuencia.

Es claro que la relación con el etnógrafo propone un escenario de esas características. No tanto porque la figura de éste lo sea por sí misma, sino por las posibles (y temidas) vinculaciones institucionales y políticas que su presencia sugiere. Arropada por estas suspicacias, la mirada indagadora del antropólogo se vuelve doblemente provocadora: amenazante en lo que tiene de búsqueda de información, desafiante en lo que tiene de emuladora de pericias.

Si el policía es ese sujeto institucionalmente preparado para el manejo de la intimidación y el control, poseedor de un saber específico en el arte de la interrogación y sus ramificaciones, la relación con la indagación etnográfica subvierte el sentido de esa competencia policial en términos de prerrogativa profesional. El etnógrafo no sólo aparece duplicando sus habilidades. A fuerza de preguntas y observaciones, los enfrenta además en su propio rol, incomodándolos con el ejercicio de su mismo oficio. Interpelados, despliegan sus propias destrezas. Vale decir, oponen la pistola al grabador. La imagen es deudora de la idea: la de re-acomodar, en un mismo movimiento, el correcto orden de las cosas, colocando al etnógrafo en situación de disparidad y devolviendo al policía al lugar de poder que éste parece disputarle.

\section{EL ROL ETNOGRÁFICO EN DISPUTA}

La figura del antropólogo sospechado fue, en los (recurrentes) inicios de mi trabajo de campo, una constante. Lejos de entender esa construcción como simple consecuencia de los avatares de un análisis en el ámbito policial, mi intención fue, en este trabajo, desarmarla en sus componentes de sospecha, recelo e intransigencia y presentarla no sólo como dato de un contexto sensible,

20 Los "chistes", es claro, dependen de un contexto de permisión especial. En el caso puntual de la asignatura mencionada, lo particular de la temática, unido a una docente co-generacional, sin dudas habilitaba cierta flexibilidad en las prácticas y comentarios de los alumnos.

21 Para profundizar en la cuestión del cinismo y el humor negro policial, ver Young (1995). 
sino como una instancia a partir de la cual los sujetos enfrentan al etnógrafo y al proceso de investigación.

Argumentaba, anteriormente, que el rol de investigación no resulta una instancia bajo el puro control del antropólogo. Este rol, antes bien, es altamente permeable a las acciones de los sujetos en el campo: desdibujado, disputado y confrontado, el rol del etnógrafo resulta entonces, en virtud de esta pugna de habilidades y competencias, una suerte de empresa en colaboración.

Se recordará a aquel director que se negaba a darme ciertas cifras relativas a la cantidad de alumnos. Vale decir que esa "obstaculización” fue sólo el preámbulo a otras varias. Había conseguido su permiso para realizar algunas entrevistas a alumnos en el predio mismo de la escuela, una vez finalizadas las horas de clase. Una tarde estaba allí, según lo pautado, y el director se recusó, de plano y sin mediación de demasiadas explicaciones, a la continuación de las entrevistas:

"No, otro Aspirante 22 no. Ya basta. Ya ahí en mi discurso tiene lo que es ser policía. Ya ahí tiene todo. Todos piensan igual, todos le van a decir lo mismo. No les puede preguntar a ellos porque ellos no saben nada. ¿Quiere que le cuente yo por qué me metí a policía? Porque mi papá me dijo: estudiás o trabajás. El era comisario. Y yo dije: ¿trabajar? Por eso. Veintitrés años en la Policía. Yo entré porque me pegaban una patada en el traste si no estudiaba".

El relato de su experiencia de ingreso a la policía clausuraba cualquier intento de recabar otras. Ante la declaración de una vivencia homogénea - "todos piensan igual, todos le van a decir lo mismo" - la intencionalidad de mi estudio se revelaba inútil. Tal declaración postulaba una limitación insalvable. Mi ejercicio de entrevistar a tales alumnos se terminó abruptamente; mi trabajo de campo debió ensayar nuevos recorridos y nuevas estrategias. ${ }^{23}$ Meses después, cuando telefoné a la escuela para interesarme por el estado de una solicitud de planes de estudio que había iniciado a través de otra dependencia, ya no recuerdo si el mismo director o uno de sus secretarios me recordó que

22 Tal es la denominación que recibían los alumnos en el Curso Preparatorio para Agentes (Escuela de Suboficiales y Agentes, PFA).

23 Tal vez sea momento de aclarar que las limitaciones y obstáculos que hallamos en el campo no deben conceptualizarse, necesariamente, como caminos sin salida en el curso de la investigación. Los datos "faltantes" - se recordará el caso de la cifra de alumnos totales de la escuela - no constituyen carencias irreparables para la investigación: no se trata de piezas ausentes que vuelven imposible la figura total de un rompecabezas. El campo, en tanto construido a partir de las relaciones establecidas y los datos originados a partir de ellas, no es nunca una falta, sino una trama producida con los recursos efectivamente disponibles. Al hablar de limitaciones, por lo tanto, lo que pretendo es colocar el énfasis no en el accionar del antropólogo y su incapacidad para "conseguir un dato", sino en el accionar del otro y su capacidad para intervenir en el proceso de investigación. Para un mayor desarrollo de este punto y su significación como dato mismo del campo, ver Sirimarco (2010). 
hacía tiempo que no me veían por allí: “¿cuándo va a volver a hacer las entrevistas?" Comencé nuevamente con ellas, sin pedir explicaciones retrospectivas ni intentar comprender lo sucedido, con una quietud temerosa de que cualquier movimiento de mi parte pudiera hacer tambalear la situación reanudada.

Las entrevistas continuaron hasta la terminación del curso, sin que nunca supiera el motivo de tales interrupciones y continuidades. Los desencadenantes pudieron ser variados y el foco tanto pudo estar en mis actitudes como en las del director, sin olvidar por supuesto los vaivenes internos del contexto policial y sus estructuras siempre fluctuantes de poder (Hathazy 2010). Independientemente de las razones que llevaron a un trabajo de campo en tales condiciones, lo importante, a los fines de este trabajo, radica en subrayar el carácter fragmentado de tal proceso de investigación, donde las características que adquirió el recorrido - negado, pausado, prorrogado - no pueden entenderse como instancias bajo exclusiva voluntad y planeamiento del etnógrafo.

La intervención limitante de los sujetos es sin dudas polisémica. Da cuenta de fastidios personales o de inquietudes institucionales. Habla a las claras, sin embargo, de una actitud destinada a posicionarse respecto del proceso investigativo, negociando sus caminos y estrategias según motivaciones individuales o intereses colectivos. Lo que hace el director de la escuela, rechazando el permiso para más entrevistas y concediéndolo nuevamente, es justamente dictar también él los tiempos del análisis, pautar también él las particularidades de su desarrollo e intervenir, en suma, en el proceso mismo de investigación.

En esta empresa en colaboración, disputar el rol del etnógrafo es también otra manera de intervenir en el curso del análisis. Durante mi trabajo de campo en la Escuela Superior, había una profesora, formada en una disciplina humanística en una universidad nacional y a la vez personal policial, que parecía sentirse incomodada por mi presencia en el aula. Su amabilidad para conmigo no estaba exenta de intervenciones destinadas a testear mis conocimientos. Frecuentemente, en medio de la clase, me dirigía preguntas, a la par que aclaraba, ante la concurrencia: "porque ella tiene el rol de observar y no intervenir, pero supongo que la Licenciada debe poder hilvanar cuatro palabras seguidas". Las preguntas, vale aclarar, sólo servían para dejar al descubierto mi ignorancia. Una vez, por ejemplo, mientras explicaba ciertas cuestiones relacionadas con la Reforma Protestante, detuvo su monologar y mirándome, me dijo:

Profesora: Acá vos nos podés explicar la Reforma.

Mariana: No tengo ni idea de la Reforma.

P: Pero, Licenciada, ¿qué me hace?

M: Soy Licenciada en Antropología, no en Historia.

"Pero cómo, Licenciada, ¿no sabe?", era el repetido comentario con que recibía mis disculpas y mi ignorancia. Su continuo interrogarme parecía ejecutar 
un movimiento doble: reforzaba su papel de profesora ubicándome en el espacio del no saber. La disputa por éste era en realidad el método de comprobación de la insuficiencia, donde lo más importante no fuera tal vez detentar un cierto conocimiento, sino resaltar la existencia de sus (mis) limitaciones. En ese intento de la profesora por testearme y hasta impugnarme subyacía, claramente, la intencionalidad mayor de socavar mi supuesto lugar de autoridad y de marcar, sobre todo, los límites de mi aceptación en el campo (Escolar 2005).

Se ha dicho largamente que la autoridad etnográfica es una ficción. Los ejemplos mencionados no hacen sino poner esta afirmación en evidencia, ilustrando cómo el status del antropólogo en el campo - sus posibilidades, sus aciertos, sus limitaciones - es una construcción vincular, donde su aceptación no es una opción más obvia que la de su rechazo.

Postular la posibilidad de este último no implica clausurar su explicación aludiendo a la resistencia y opacidad de las instituciones policiales, ni a una suerte de "maldad" intrínseca de los sujetos en el campo, encaprichados en dificultar la tarea del antropólogo. Plausibles todas ellas, no invalidan sin embargo una motivación tal vez más primaria. La resistencia con que etnógrafo e investigación son enfrentados puede resolverse en una simple pregunta. La misma sobrevuela todas las interpelaciones dirigidas al etnógrafo: ¿quién te crees que sos vos para querer saber? O mejor dicho: ¿quién te crees que sos vos para pretender que nosotros contestemos a tus ansias de saber?

Pregunta que nos restituye, como antropólogos, a la escena de la investigación, descubriéndonos una determinada imagen de las ciencias sociales en general y del método etnográfico en particular. La pregunta es similar a la de Cuol: “¿qué harás con el nombre de mi linaje, si te lo digo?”. Vernos a través de los ojos de Cuol o de los policías permite entonces avanzar en dos reflexiones absolutamente paralelas. La primera permite dislocar la construcción de la paranoia de los otros y matizar con nuevos sentidos la figura del antropólogo sospechado. Permite, sobre todo, articular la investigación de campo con las relaciones de poder que le subyacen, recolocando en un plano político la cuestión metodológica de la etnografía y su pretensión de inmersión en la vida de los otros.

La segunda permite examinar el sentido y el papel que este recelo y este desafío - del propio investigador, del propio análisis - adquieren en la producción del conocimiento antropológico. El objetivo pretende ser doble: colocar y significar este enfrentamiento en un contexto epistemológico, pero hacerlo de tal modo que éste no se convierta, en el texto etnográfico, en una mera estrategia metodológica o retórica destinada a resaltar, finalmente, la autoridad de la disciplina o del investigador (Fabian 1995). Los modos con que los otros nos disputan no debieran conceptualizarse qua pruebas que, una vez superadas, templan aun más la relevancia del etnógrafo, sino como asperezas reales que la cuestionan cotidianamente. 
Como bien nos sugieren Cuol y los policías de este relato, el proceso de investigación antropológica no se da sin devaneos. El campo no es una instancia mansa a la espera de la observación del etnógrafo, sino el resultado de encuentros y confrontaciones. Y tanto el análisis como el rol del investigador son una empresa en colaboración, donde investigador e informantes - policías y etnógrafo -, en el ejercicio siempre continuo de encontrarnos, resistirnos y limitarnos, nos construimos mutuamente.

\section{BIBLIOGRAFÍA}

CASTRO, Celso, y Piero LEIRNER, 2009, Antropologia dos Militares: Reflexões sobre Pesquisas de Campo. Rio de Janeiro, Editora FGV.

CLIFFORD, James, y George MARCUS (comps.), 1986, Writing Culture: The Poetics and Politics of Ethnography. Berkeley y Los Angeles, University of California Press.

DAICH, Deborah, y Mariana SIRIMARCO, 2009, "Anita anota: el antropólogo en la aldea (penal y burocrática)", Cadernos de Campo, 18 (18), 13-28.

ESCOBAR, Raúl Tomás, 1979, Manual de Inteligencia, tomo I. Buenos Aires, Editorial F. I.

— 1987, El Interrogatorio en la Investigación Criminal. Buenos Aires, Editorial Universidad.

ESCOLAR, Diego, 2005, "La soberanía en el campo: poder, etnografía y secreto en los Andes sanjuaninos", en Guillermo Wilde y Pablo Schamber (comps.), Historia, Poder y Discursos. Buenos Aires, Paradigma Indicial, 49-76.

EVANS-PRITCHARD, Edward Evan, 1987, Los Nuer. Barcelona, Anagrama.

FABIAN, Johannes, 1995, "Ethnographic misunderstanding and the perils of context", American Anthropologist, 97 (1): 41-50.

FONSECA, Claudia, 2000, Família, Fofoca e Honra: Etnografía de Relações de Gênero e Violência em Grupos Populares. Porto Alegre, UfRGS.

GINZBURG, Carlo, 2006, "L'inquisitore come antropólogo", en Carlo Ginzburg, Il Filo e le Tracce: Vero, Falso, Finto. Milàn, Feltrinelli, 270-294.

GUBER, Rosana, 2001, La Etnografia: Método, Campo y Reflexividad. Bogotá, Grupo Editorial Norma.

HATHAZY, Paul, 2010, "Los caminos de la opacidad: accesibilidad y resistencia en el estudio de las organizaciones policiales como obstáculo y dato", en Mariana Sirimarco (comp.), Estudiar la Policía: La Mirada de las Ciencias Sociales sobre la Institución Policial. Buenos Aires, Editorial Teseo, 139-177.

HERBERT, Steve, 2001, "From spy to okay guy: trust and validity in fieldwork with police", Geographical Review, 91 (1-2): 304-310.

KANDEL, Randy Frances, 1992, "How lawyers and anthropologists think differently: six differences in assumptions and outlook between anthropologists and attorneys", Napa Bulletin, 11: 1-81. 
LEIRNER, Piero, 2009a, "Etnografia con militares: fórmula, dosagem e posologia”, en Celso Castro y Piero Leirner (comps.), Antropologia dos Militares: Reflexões sobre Pesquisas de Campo. Rio de Janeiro, Editora FGV, 31-51.

— 2009 b, "A etnografia como extensão da guerra por outros meios: nota sobre a pesquisa com militares", Mana, 15 (1): 59-89.

MARCUS, George E., y Michael M.J. FISCHER, 1986, Anthropology as Cultural Critique: An Experimental Moment in the Human Sciences. Chicago y Londres, University of Chicago Press.

MENDES DE MIRANDA, Ana Paula, 2001, "Segrados e mentiras, confidências e confissões: reflexões sobre a representação do antropólogo como inquisidor", Comum, 6 (17): 91-110.

— 2005, "Antropologia, Estado moderno e poder: perspectivas e desafios de um campo em construção", Avá: Revista de Antropología, 7: 128-146.

OWENS, Geoffrey Ross, 2003, "What! Me a spy? Intrigue and reflexivity in Zanzibar", Ethnography, 4 (1): 122-144.

PRICE, David, 2002a, "Past wars, present dangers, future anthropologies", Anthropology Today, 18 (1): 3-5.

— $2002 \mathrm{~b}$, "Lesson from Second World War anthropology: peripheral, persuasive and ignored contributions", Anthropology Today, 18 (3): 14-20.

— $2002 \mathrm{c}$, "Interlopers and invited guests: on anthropology's witting and unwitting links to intelligence agencies, Anthropology Today, 18 (6): 16-21.

ROSALDO, Renato, 1991, "Desde la puerta de la tienda de campaña: el investigador de campo y el inquisidor”, en James Clifford y George Marcus (comps.), Retóricas de la Antropología. Madrid, Ediciones Júcar, 123-150.

SIRIMARCO, Mariana, 2006, Corporalidades: Producción (y Replicación) del Cuerpo Legítimo en el Proceso de Construcción del Sujeto Policial, Facultad de Filosofía y Letras, Universidad de Buenos Aires, tesis de doctorado en Ciencias Antropológicas.

— 2009, De Civil a Policía: El Proceso de Incorporación a la Institución Policial. Buenos Aires, Editorial Teseo.

— 2010, "Introducción", en Mariana Sirimarco (comp.), Estudiar la Policía: La Mirada de las Ciencias Sociales sobre la Institución Policial. Buenos Aires, Editorial Teseo, 9-25.

SZASZ, Thomas, 1977, "A quién sirve la psiquiatría? Del matadero manicomio; lenguaje, ley y locura", en Franco Basaglia y Franca Basaglia Onforo (comps.), Los Crímines de la Paz, México, DF, Siglo XXI, 309-320.

TISCORNIA, Sofía, 1992, “Antropología política y criminología: acerca de la construcción de dominios en el control de la 'otredad'”, Publicar: Antropología y Ciencias Sociales, 1 (1): 53-68.

VAN MAANEN, John, 1978, “Epilogue: on watching the watchers", en Peter Manning y John Van Maanen (comps.), Policing: A View from the Street. Santa Mónica, Goodyear Publishing Company, 309-349.

WRIGHT, Susan, 2007, "Spying and fieldwork: a response to Heike Schaumber", Anthropology Today, 23 (1): 28-28.

YOUNG, Malcolm, 1995, "Black humour: making light of death", Policing and Society, 5: $151-167$.

ŽIŽEK, Slavoj, 2000, Mirando al Sesgo: Una Introducción a Jacques Lacan a través de la Cultura Popular. Buenos Aires, Editorial Paidós. 